\title{
A new cave dwelling Duvalius from the Aurunci Mountains (Lazio) (Coleoptera: Carabidae)
}

\author{
Paolo MAGRINI ${ }^{1, *}$,Valerio SBORDONI ${ }^{2}$ \\ ${ }^{1}$ Museo di Storia naturale dell'Università di Firenze, Sezione di Zoologia “La Specola” - Via Romana 17, I-50125 Firenze, Italy; \\ or: Via Gianfilippo Braccini 7, I-50141 Firenze, Italy - duvalius@paolomagrini.it \\ ${ }^{2}$ Department of Biology - Tor Vergata University, I-00133 Roma, Italy - valerio.sbordoni@uniroma2.it \\ * Corresponding author
}

\begin{abstract}
A new anophthalmic carabid beetle belonging to the genus Duvalius Delarouzée, 1859, recently collected in a deep cave in the Southern Aurunci Mountains, Lazio, is described. The new species appears to be the most troglomorphic among all the thus far known Italian Duvalius.
\end{abstract}

Key words: Carabidae, Duvalius dellermae, new species, Italy, troglobitic fauna.

urn:Isid:zoobank.org:pub:92B7FE36-988A-4E35-997F-8D646D1DFE8B

\section{Introduction}

Recently we have had the opportunity to study an anophthalmic carabid beetle belonging to the genus Duvalius Delarouzée, 1859, collected in a deep cave in the Southern Aurunci Mountains, Lazio.

The studied specimen is to be referred to a new species, represents the most troglomorphic Italian Duvalius, and exhibits some somatic traits of the 'Aphaenopsian type'. In this brief note we provide its description.

\section{Materials and Methods}

The materials used in this work are deposited in the collections listed below with their respective acronyms.

CM Coll. P. Magrini (Florence);

CVT Coll. Vigna Taglianti (Genoa);

MSNG Coll. "Giacomo Doria" Civic Museum of Natural History (Genoa).

We also report below the abbreviations of the morphometric measures shown in the Table and in the description. $\mathbf{L}$ overall length, from the apex of the jaws to the end of the elytra;

HMW maximum head width at time swelling;

LA length of the antennas;

PL length of the pronotum, measured along the midline;

PMW maximum width of the pronotum;
PB width of the base of the pronotum;

EL elytra length, measured from the periscutellar bristle to the sutural angle;

EW maximum width of the wings;

PMW/PL maximum width/length ratio of the pronotum;

EL/EW length/width ratio of the wings;

EW/PMW elytra width/pronotum width ratio;

LE aedeagus length;

LP lamella copulatrix length;

AN antennal article length.

The macrophotographs in the text were taken by one of us (PM) using a Nikon D800 or Nikon D2X digital camera, applied on a Nikon Labophot II binocular optical microscope or Nikon SMZ 1000 stereomicroscope, with diaphragm lenses.

Duvalius dellermae n. sp. (Figs 1-5, 9, 11)

Locus Typicus. Italy: Lazio, Southern Aurunci Mountains, Pandora Cave, $N^{\circ} 1850$ La/LT, 1225 m, locality Fosse di Sola, plateau between Monte Redentore and Monte Altino (Maranola, Latina). Coordinates UTM WGS 84: 3858954573991.

Type series. Holotypus: male, Italy: Lazio, Southern Aurunci Mountains, Pandora Cave, $\mathrm{N}^{\circ} 1850 \mathrm{~L} / \mathrm{LT}, 1225 \mathrm{~m}$ a.s.l., locality Fosse di Sola, plateau between Monte Redentore and Monte Altino (Maranola, Latina). Coordi- 
nates UTM WGS 84: 385895 4573991. 6.VI.2013, Federica Dellerma legit (CM).

\section{Description}

A medium-sized blind Duvalius (total length from the apex of the jaws to the end of the elytra $5 \mathrm{~mm}$ ), of a uniform light yellow colour. General delicate aspect, with very elongated appendages (Fig. 1).

Narrow and elongated head (maximum width 0.77 $\mathrm{mm})$. Frontal furrows complete, shallow and not very arched, irregular. Ocular region represented by a medium-sized whitish roundish areola. Long temples, not very convex, non-pubescent. Cephalic chaetotaxy without significant peculiarities. Very long and thin antennas: 4.14 $\mathrm{mm}$, including 1.20 times in the total body length. Labrum slightly hollowed, three-lobed, the median lobe just hinted. Glossy integuments with very superficial polygonal micro-sculpture which is perceptible only in a few points. Narrow and elongated pronotum, cordiform, with slightly rounded anterior and sharply sinuous sides before the posterior corners, glabrous, slightly wider than long: maximum width $1.06 \mathrm{~mm}$; base width $0.67 \mathrm{~mm}$; midline length $0.96 \mathrm{~mm}$; ratio between maximum width and length 1.10. Obtuse and salient anterior pronotal angles; almost straight rear corners, with sharp apex. Wide and regular side groove. Of the marginal bristles, the anterior ones approximately at the first third, at the point of greatest width of the pronotum; the basal bristles just before the rear corners, clearly behind the point of greatest narrowing of the pronotum, in a marginal position. Deeply incised median sulcus, also numerous wrinkles on the sides of the pronotum. Very superficial and almost invisible microsculpture. Very elongated oval elytra, convex, non-pubescent; overall width $1.67 \mathrm{~mm}$; length from the peri-scutellar bristle to the apex $2.63 \mathrm{~mm}$; length to width ratio 1.57 . Widely obtuse, vanished, aphaenopsian humers; basal line of the elytra clearly oblique. Large and regular elytral gutter. Elytral streaks formed by series of clearly visible points,

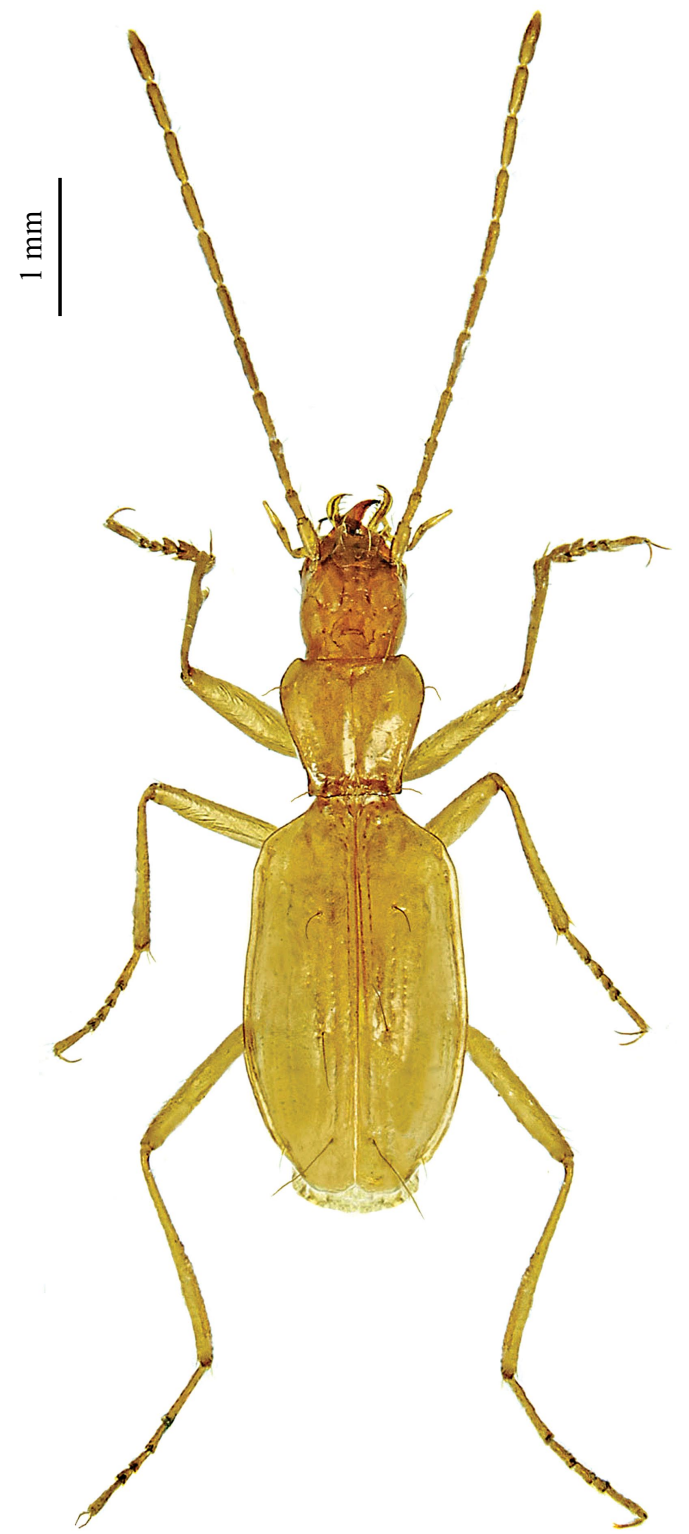

Fig. 1 - Duvalius dellermae n. sp. (Holotypus đ̂̉): habitus (CM).

Table 1 - Morphometric data of Duvalius dellermae n. sp., Holotypus, and a sample of the most related species: Duvalius auruncus Vigna Taglianti \& Magrini, 2008 from the Grava dei Serini $N^{\circ} 587$ La / FR (Esperia, Frosinone). N=12 measured males.

\begin{tabular}{|c|c|c|c|c|c|c|c|c|c|c|c|c|c|c|c|c|c|c|}
\hline & $\mathrm{L}$ & LA & $\frac{\mathrm{L}}{\mathrm{LA}}$ & PMW & PL & PB & $\frac{\mathrm{PMW}}{\mathrm{PL}}$ & EL & EW & $\frac{\mathrm{EL}}{\mathrm{EW}}$ & $\frac{\text { EW }}{\text { PMW }}$ & $\begin{array}{l}\text { LE } \\
\text { LP }\end{array}$ & HMW & $\begin{array}{c}\mathrm{AN} \\
1^{\circ}\end{array}$ & $\begin{array}{c}\mathrm{AN} \\
2^{\circ}\end{array}$ & $\begin{array}{c}\mathrm{AN} \\
3^{\circ}\end{array}$ & $\begin{array}{c}\mathrm{AN} \\
4^{\circ}\end{array}$ & $\begin{array}{l}\text { AN } \\
11^{\circ}\end{array}$ \\
\hline $\begin{array}{l}\text { Holotypus } \\
\text { D. dellermae }\end{array}$ & 5 & 4,10 & 1,20 & 1,06 & 0,96 & 0,67 & 1,10 & 2,63 & 1,67 & 1,57 & 1,57 & $\begin{array}{l}1,18 \\
0,55\end{array}$ & 0,77 & 0,32 & 0,21 & 0,40 & 0,37 & 0,40 \\
\hline $\begin{array}{l}\text { Holotypus } \\
\text { D. auruncus }\end{array}$ & 5,99 & 4,28 & 1,40 & 1,16 & 1,06 & 0,77 & 1,09 & 3,18 & 1,90 & 1,68 & 1,64 & $\begin{array}{l}1,08 \\
0,61\end{array}$ & 0,87 & 0,32 & 0,26 & 0,44 & 0,40 & 0,40 \\
\hline min. & 5,39 & 3,95 & 1,34 & 1,06 & 1 & 0,71 & 1,06 & 2,96 & 1,77 & 1,64 & 1,62 & $\begin{array}{l}1,08 \\
0,55\end{array}$ & 0,79 & 0,31 & 0,24 & 0,37 & 0,35 & 0,39 \\
\hline $\max$ & 5,99 & 4,28 & 1,43 & 1,16 & 1,06 & 0,77 & 1,10 & 3,18 & 1,93 & 1,71 & 1,71 & $\begin{array}{l}1,19 \\
0,61\end{array}$ & 0,87 & 0,34 & 0,27 & 0,44 & 0,42 & 0,40 \\
\hline mean & 5,74 & 4,09 & 1,40 & 1,11 & 1,02 & 0,74 & 1,09 & 3,09 & 1,85 & 1,67 & 1,66 & $\begin{array}{l}1,13 \\
0,59\end{array}$ & 0,83 & 0,32 & 0,25 & 0,40 & 0,38 & 0,395 \\
\hline
\end{tabular}




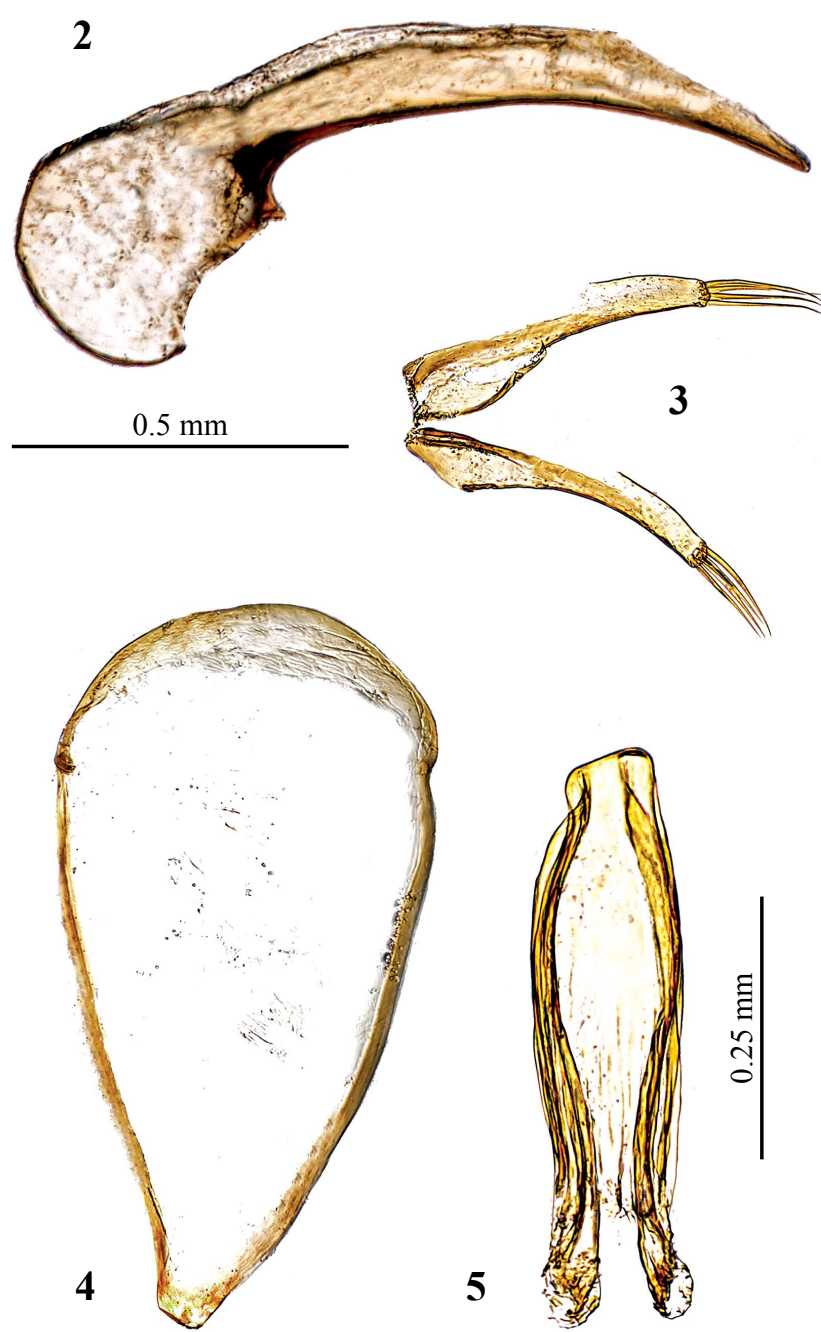

Figs 2-5 - Duvalius dellermae n. sp. (Holotypus): 2, median lobe of the aedeagus in lateral view, in euparal on vinyl acetate; $\mathbf{3}$, parameres; 4, urite IX; 5, lamella copulatrix. The first three figures are on the same scale.

all clearly visible, evanescent only in the basal and apical regions; sub-convex interstrias. Four bristles of the humeral group of the umbilical series, regularly arranged and very distant from each other, with a slight tendency to migrate towards the disc as one proceeds towards the elytral apex. Two elytral disc bristles on each side, the front at the level of the fourth humeral bristle, the rear largely apical with respect to the half of the elytra. Apical triangle without significant features. Ratio between the width of the elytra and the maximum width of the pronotum 1.57 (it is curious to note that it is identical to the EL/EW ratio). Very fine microsculpture and therefore a highly polished appearance of the elytra.

Very long and slender legs; the first two tarsomera of the front legs of the male more dilated than the following ones and inferiorly provided with adhesive phanera. Anterior tibia with wide groove and barely hinted in the anteri-
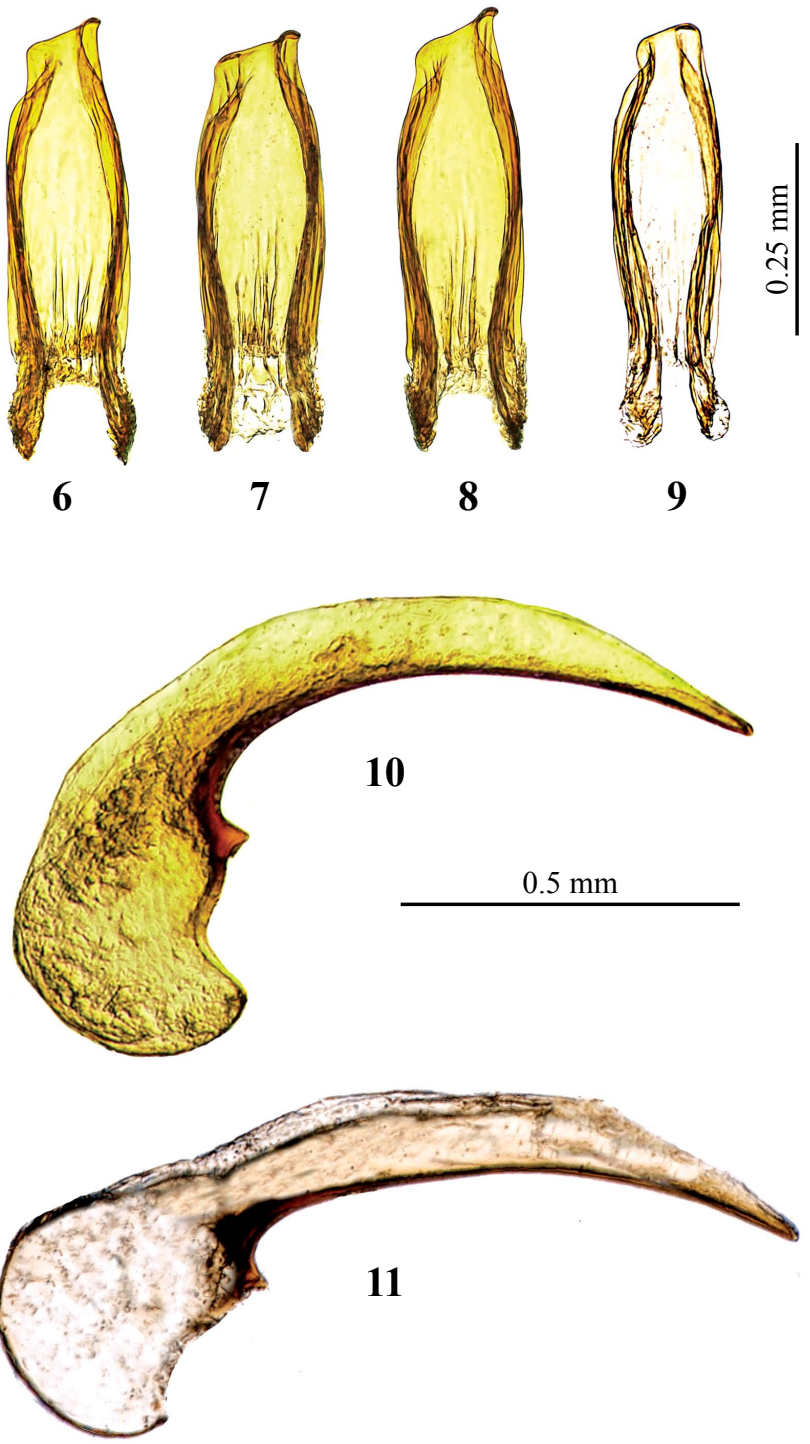

Figs 6-11 - 6, Lamella copulatrix, in euparal on vinyl acetate of: Duvalius auruncus Vigna Taglianti \& Magrini, 2008: Holotypus, Grava dei Serini N ${ }^{\circ} 587 \mathrm{La} / \mathrm{FR}$, Central Aurunci Mountains, Esperia, Frosinone (CVT-MSNG); 7, ditto, Paratypus 1 (CM); 8, ditto, Paratypus 2 (CM); 9, Duvalius dellermae n. sp., Holotypus, Lazio, Southern Aurunci Mountains, Pandora Cave N ${ }^{\circ} 1850$ La / LT, loc. Fosse di Sola, Plateau between Monte Redentore and Monte Altino (Maranola, Latina) (CM). 10-11, Aedeagus in lateral view of Duvalius spp.: 10, D. auruncus, Holotypus; 11, Duvalius dellermae n. sp., Holotypus.

or area. Very elongated tarsi, the hindquarters with the first article clearly longer than the following three.

Aedeagus in lateral vision $1.18 \mathrm{~mm}$ long, slightly arched and very elongated, with relatively small basal bulb (Figs 2 and 11). Copulating lamella gutter shaped in ventral view, narrow and elongated, robust and well sclerotized, with asymmetrical apex, the right side longer than the left (Figs 5 and 9), length $0.55 \mathrm{~mm}$; there is no unequal median phanera. Small paramera, each provided with four 

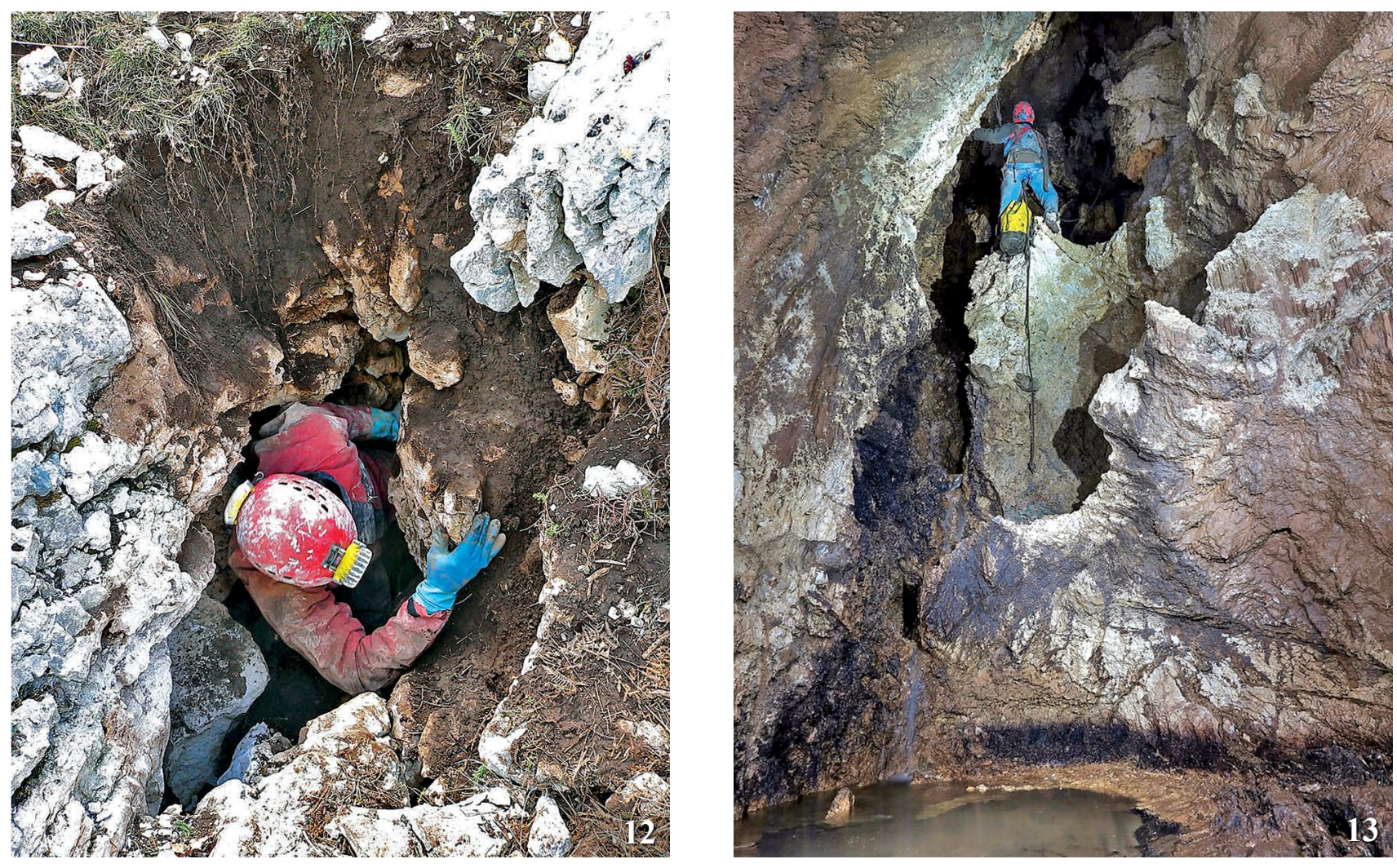

Figs 12-13 - Pandora Cave $\mathrm{N}^{\circ} 1850 \mathrm{La} / \mathrm{LT}$ : 12, entrance; 13, room at $-150 \mathrm{~m}$.

apical bristles (Fig. 3). Medium-sized, narrow and elongated ninth urite (Fig. 4).

Derivatio nominis. We are pleased to dedicate this interesting new species to its collector, Federica Dellerma, a keen speleologist of the Gruppo Grotte Castelli Romani, a team tenaciously engaged in the exploration and study of the caves of the Aurunci Mountains.

Ecological notes. The new species is known in a single male specimen, slightly immature, collected in the Pandora Cave $\mathrm{N}^{\circ} 1850 \mathrm{La} / \mathrm{LT}$, locality Fosse di Sola, Plateau between Monte Redentore and Monte Altino, Southern Aurunci Mountains (Maranola, Latina). The cave is a large karst complex consisting of a series of parallel spindles and reaches a depth of $-350 \mathrm{~m}$. The only known specimen of the new species was sampled by Federica Dellerma in free hunting at $-140 \mathrm{~m}$. Map in Fig. 14, updated from Vigna Taglianti \& Magrini (2008) shows the distribution of all Duvalius species so far known from Latium.

Comments and comparative notes. The new species is undoubtedly to be classified in the "franchettii group" (sensu Vigna Taglianti \& Magrini 2008) for the presence of two disc bristles, the absence of pubescence at the temples and on the integuments in general and the shape of aedeagus and lamella copulatrix, large and without an unequal median. It is closely related to Duvalius auruncus Vigna Taglianti \& Magrini, 2008 of the Grava dei Serini (Esperia, Frosinone) which up to now was the most special- ized Duvalius championship in Italy, however this taxon is even more troglomorphic (i.e., specialized to underground life). The remarkable degree of morphological specialization, with narrow and elongated thorax and oblique and elusive humers, allows to easily distinguish these two taxa from all the other species of the group and makes them considered as the most Aphaenopsian among the Italian ones, similar for the convergence of some characters, to the genus Agostinia Jeannel, 1928 of the Maritime Alps. The new taxon differs from Duvalius auruncus in the following characters: smaller size (5 mm against 5.39-5.99 $\mathrm{mm}$ ); longer antennas, with an L/LA ratio of 1.20, against a ratio of 1.34-1.43; proportionally longer elytra, with an $\mathrm{EL} / \mathrm{EW}$ ratio of 1.57 , compared to $1.64-1.71$; aedeagus much less arched, more elongated and with a smaller basal bulb (Figs 10-11); lamella copulatrix with a narrower and more rounded apex (Figs 6-9).

The new species is also distinct from the two endogeous species of Monte Sant'Angelo, located immediately north of the Pandora Cave: Duvalius vannii Magrini \& Sclano, 1998, of the "cerrutii group" with three disc bristles and Duvalius volscus A. Franzini \& G. Franzini, 1984, a much less troglomorphic species of the "franchettii group", characterized by a differently shaped and lanceolate lamella copulatrix.

The other two species located further north-east are even more different: Duvalius bertagnii Magrini, 1998 (in 


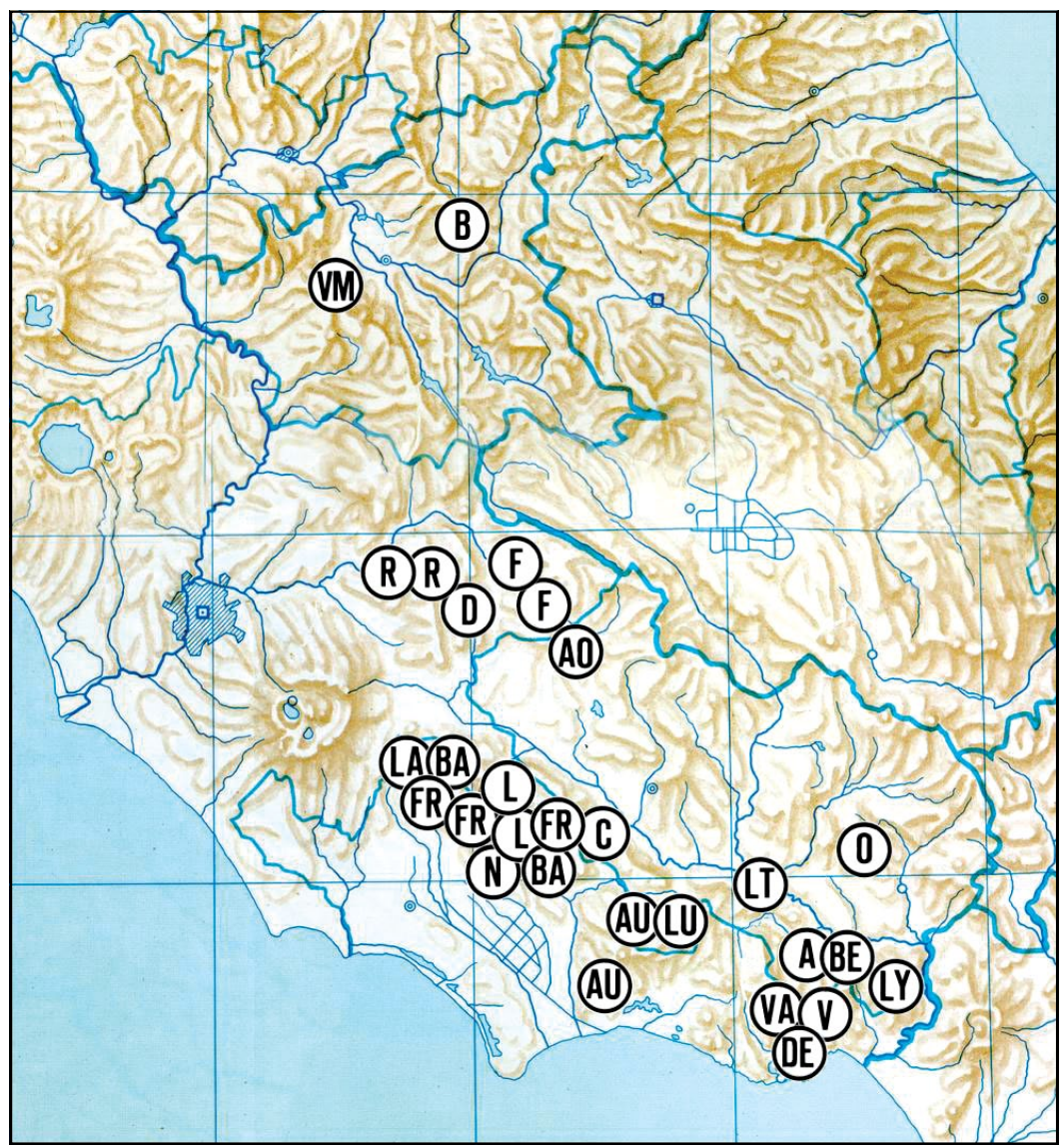

Fig. 14 - Distribution of the genus Duvalius within Lazio: F, D. franchettii (Luigioni, 1926); L, D. lepinensis Cerruti, 1950 ; LA, D. lepinensis ametistinus Magrini \& Bastianini, 2002; C, D. cerrutii Sbordoni \& Di Domenico, 1967; O, D. oscus A. Franzini \& G. Franzini, 1984; V, D. volscus A. Franzini \& G. Franzini, 1984; R, D. rossii Magrini \& Vanni, 1991; VA, D. vannii Magrini \& Sclano, 1998; BA, D. bastianinii Magrini, 1998; BE, D. bertagnii Magrini, 1998; LU, D. laurentii Magrini \& Bastianini, 2003; A, D. auruncus Vigna Taglianti \& Magrini, 2008; AU, D. ausonicus Vigna Taglianti \& Magrini, 2008; D, D. dattii Vigna Taglianti \& Magrini, 2008; AO, D. avoni Vigna Taglianti \& Magrini, 2008; LT, D. latellai Vigna Taglianti \& Magrini, 2008; FR, D. franziniorum Vigna Taglianti \& Magrini, 2008; N, D. nardii Vigna Taglianti \& Magrini, 2008; LY, D. lydiae Vigna Taglianti \& Magrini, $2008 ;$ VM, D. virginiae ssp. marinae Vigna Taglianti \& Magrini, 2008; B, D. brandmayri Vigna Taglianti \& Magrini, 2008; DE, D. dellermae Magrini \& Sbordoni n. sp.

the "cerrutii group"), large, much wider and with 5-8 disc bristles and Duvalius lydiae Vigna Taglianti \& Magrini, 2008, (in the "lydiae group"), with 2-3 disc bristles and the integument completely covered by short pubescence (instead of hairless). No apparent relationship with the other species thus far known from Lazio or from neighboring regions, as reported by: Cerruti 1950, 1955; Franzini \& Franzini 1984; Jeannel 1928; Luigioni 1926; Magrini 1997, 1998 a, b; Magrini \& Bastianini 2002, 2003; Magrini \& Sclano 1998; Magrini \& Vanni 1991; Sbordoni 1971; Sbordoni \& Di Domenico 1967; Vigna Taglianti 1982, 2001, 2005; Vigna Taglianti et al. 1993.

The discovery of this new taxon emphasizes the great value of the Aurunci Mountains (this mountain range marking the border between the Central and the Southern Apennines) as a treasure trove of biodiversity, biogeographically characterized by the presence of several endemic taxa.
Acknowledgements - We wish to thank Federica Dellerma who collected the first and so far the sole specimen of this new Duvalius, and extend our thanks to the members of the 'Gruppo Speleologico Castelli Romani' who are building up a fundamental contribution to the speleological exploration of the Aurunci Mountains.

\section{References}

Cerruti M. 1950. Nuovi reperti di Coleotteri in caverne laziali. Rassegna Speleologica Italiana, 2 (3): 131.

Cerruti M. 1955. Validità specifica del Duvalius (s.str.) Franchettii lepinensis Cerruti (Coleopt - Carabidae). Fragmenta entomologica, 2 (2):17-24.

Franzini A., Franzini G. 1984. Due nuove specie di Duvalius Del. dell'Appennino Centrale (Coleoptera Carabidae). Giornale italiano di Entomologia, 2: 175-180.

Jeannel R. 1928. Monographie des Trechinae (Troisième livraison). Les Trechini cavernicoles. L'Abeille, Paris, 35: 1-808. 
Luigioni P. 1926. Un nuovo «anoftalmo» dell'Italia centrale (Coleoptera - Fam.Carabidae). Atti della Pontificia Accademia delle Scienze Nuovi Lincei, 79 (6): 166-169.

Magrini P. 1997. Première révision des Duvalius s. str. Italiens (Coleoptera, Carabidae, Trechinae). Les Comptes-rendus du L.E.F.H.E., 2: 202-291.

Magrini P. 1998a. Première révision des Duvalius s. str. italiens (deuxième partie: atlas biogéographique des Duvalius italiens; ajouts et corrections de la première partie) (Coleoptera, Carabidae, Trechinae). Les Comptes-rendus du L.E.F.H.E., 3: 55-149.

Magrini P. 1998b. Diagnose préliminaire de deux nouveaux Duvalius (s. str.) du Latium (Coleoptera, Carabidae, Trechinae). Les Comptes-rendus du L.E.F.H.E., 3: 151-159.

Magrini P., Bastianini M. 2002. Una nuova sottospecie del genere Duvalius del Lazio meridionale (Italia) (Coleoptera: Carabidae: Trechinae). Acta Entomologica Slovenica, 10 (2): 185-192.

Magrini P., Bastianini M. 2003. Un nuovo Duvalius del "gruppo cerrutii" (sensu Magrini, 1997) del Lazio meridionale (Italia) (Coleoptera: Carabidae: Trechinae). Acta Entomologica Slovenica, 11 (1): 31-39.

Magrini P., Sclano G. 1998. Un nuovo Duvalius del Lazio (Coleoptera, Carabidae, Trechinae). Acta Entomologica Slovenica, 6 (1): 47-54.

Magrini P., Vanni S. 1991. Descrizione di una nuova specie di
Duvalius del Lazio, Italia (Coleoptera, Carabidae: Trechinae). Opuscula zoologica fluminensia, 75: 1-6.

Sbordoni V. 1971. Osservazioni biogeografiche sulla fauna cavernicola dell'Appennino Centrale. Lavori della Società italiana di Biogeografia, (n.s.) 2: 595-614.

Sbordoni V., Di Domenico N. 1967. Una nuova specie cavernicola di Duvalius dell'Appennino centrale (Coleoptera, Carabidae). Fragmenta entomologica, 5: 165-180.

Vigna Taglianti A. 1982. Le attuali conoscenze sui Coleotteri Carabidi cavernicoli italiani. Lavori della Società italiana di Biogeografia, (n.s.) 7 (1978): 339-430.

Vigna Taglianti A. 2001. La fauna dei Monti Prenestini ed il suo significato biogeografico, pp. 233-246. In: Angelici F.M. (ed.), Aspetti naturalistici dei Monti Prenestini, Associazione Naturalistica "Orchidea" - Genazzano (Roma), Regione Lazio - Assessorato Ambiente, xviii + 270 pp.

Vigna Taglianti A. 2005. Checklist e corotipi delle specie di Carabidi della Fauna Italiana, pp. 186-225. In: Brandmayr P., ZettoT., Pizzolotto R., I Coleotteri Carabidi per la valutazione ambientale e la conservazione delle biodiversità. Manuali e Linee Guida, 34, APAT, Roma, 240 pp.

Vigna Taglianti A., Magrini P. 2008. Dieci nuovi Duvalius del Lazio. Fragmenta entomologica, 40 (1): 9-81.

Vigna Taglianti A., Magrini P., Vanni S. 1993. Descrizione di un nuovo Duvalius del Matese (Caserta). Fragmenta entomologica, 24: 147-157. 